\title{
The Use of Oyster Shell Powders for Water Quality Improvement of Lakes by Algal Blooms Removal
}

\author{
Jae-Hoon Huh, Young-Hoon Choi*, Hyun-Jae Lee ${ }^{* * *}$, Woo Jeong Choi***, Chilakala Ramakrishna, \\ Hyoung-Woo Lee, Shin-Haeng Lee*, and Ji-Whan Ahn****; \\ Dept. of R\&D Team, Hanil Cement Corporation, Danyang 27003, Korea \\ *Dept. of R\&D Team, Daesung MDI, Danyang 27016, Korea \\ **Dept. of Bio-based Materials, Chungnam National University, Daejeon 34134, Korea \\ ***Dept. of Environment and Forest Resources, Chungnam National University, Daejeon 34134, Korea \\ ****Mineral Processing Division, Korea Institute of Geoscience and Mineral Resources, Daejeon 34132, Korea \\ (Received December 8, 2015; Revised January 19, January 22, 2016; Accepted January 25, 2016)
}

\begin{abstract}
In this year, Koreans have a shortage in agricultural and drinking water due to severe algal blooms generated in major lakes. Waste oyster shells were obtained from temporary storage near the workplace at which oysters were separated from their shells. Heating $\left(1000^{\circ} \mathrm{C}\right.$ for $1 \mathrm{~h}$ in air) was employed to convert raw oyster shell powders into calcium oxide powders that reacted efficiently with phosphorus and nitrogen to remove algal blooms from eutrophicated wastewater. As the dispersed amount of heated oyster shell powders was increased, water clarity and visual light penetration were improved. Coagulation, precipitation and carbonation process of the heated oyster shell powders in a water purifier facilitated removal of eutrophication nutrient such as phosphorus and nitrogen, which is both beneficial and economically viable. $\mathrm{CO}_{2}$ implantation by carbonation treatment not only produced thermodynamically stable $\mathrm{CaO}$ in oyster shells to derive precipitated calcium carbonate (PCC) but also accelerated algal removal by activation of coagulation and precipitation process. The use of oyster shell powders led to a mean reduction of $97 \%$ in total phosphate (T-P), a mean reduction of $91 \%$ in total nitrogen (T-N) and a maximum reduction of $51 \%$ in chemical oxygen demand (COD), compared with the total pollutant load of raw algal solution. Remarkable water quality improvement of algal removal by heated oyster shell powders and PCC carbonation treatment will allow utilization as water resources to agricultural or industrial use.
\end{abstract}

Key words : Oyster shell, Water quality, Algae, Phosphorus, Nitrogen

\section{Introduction}

O yster farming industry of South Korea produces goods for overseas export $60 \%$ of which are sold in the form of canned, dried raw and frozen oyster generating a profit over $\$ 100$ million every year. Further, the industry has been activated enough to take charge of an important role in domestic market as well as regional economy of south coast. ${ }^{1)}$ However, large amounts of waste oyster shells which are released exponentially along with activation of the oyster farming industry have been dealt with them as ocean waste as in world-famous beaches. The domestic disposal amount of waste oyster shells are reached to about 300 thousand tons, and the half of those amounts are not being recycled. Ultimately, they are left unattended by being fieldheaped on the seaside in the form of shore landfill or seaside dumping due to the difficulty in securing landfill sites or

${ }^{\dagger}$ Corresponding author : Ji-Whan Ahn

E-mail : ahnjw@kigam.re.kr

Tel : +82-42-868-3578 Fax : +82-42-861-3990 lack of economic support for recycling, etc.. ${ }^{2}$ However, waste oyster shells are considered as an important recycling resource which can substitute for the finite resource of limestone. Especially, considering and hence considering South Korea's situation lacking in endowed resources is required a new breakthrough for massive treatment. Active studies on waste oyster shell have been conducted for utilization mainly in phosphate removal, ${ }^{3)}$ concrete aggregate and backfill, ${ }^{4,5)}$ sand mixture, ${ }^{6)}$ cement mortar and clinker, ${ }^{7-9)}$ filter bed and heat retardant coating, ${ }^{10,11)}$ eutrophication control, ${ }^{12)}$ as well as algae and phosphorus removal. ${ }^{13)}$

South Korea suffered a serious drought in 2015 due to the low rainfall which failed to reach even half of the ordinary year's rainfall as a result of climate change. Whereas the phenomenon of water shortage has been drastically increased by $144 \%$ in last 10 years, the capability to preserve water resources has been increased only by $15 \% .{ }^{14}$ Water resource management such as removal of algal bloom which pollutes the water to green color, etc. is essential as the high occurrence frequency of algae causing the phenomenon of intensified algal bloom have been increased by as much as 10,000 times as of September, 2015 this year com- 
pared with $2013 .{ }^{15,16)}$ Specifically, algae is rapidly grown to form algal bloom called green tide when the major crucial nutrients produced as a result of human activities provide an eutrophication environment due to their inflow into rivers or brooks. ${ }^{17)}$ Such eutrophication is being reported to have a problem of being able to generate an environment which allows excessive multiplication of algae as the primary underwater producer and a particular toxic blue-algal bloom(cyanobacteria) to take predominance. ${ }^{18,19)}$

Recently, environmental controversy is being continued that primary reason of present water quality pollution may be because 16 water reservoirs constructed in 4 Rivers Project block natural water flow of the river. The present study has been conducted with an objective to improve water quality of major lakes or rivers of the South Korea where microalgae are rapidly increased in summer. The waste oyster shells which were heaped on the seas shore of south coast was pulverized to constant sized particle shape and was calcined to improve the reactivity in raw algae solution. The changes in water clarity and light penetration of the polluted water dispersed according to masses of the calcined particle of waste oyster shells were observed after or for prompt treatment of the algal contamination which is blocking dissolution of oxygen by being distributed mainly on the upper side of water. To elucidate water quality improvement of the water polluted with algal bloom using the calcined particle of waste oyster shells, experiments in total phosphorous and total nitrogen and chemical oxygen demands through coagulation and precipitation of the algal contamination were conducted. Also, conversion to precipitated calcium carbonated powders was attempted to fix $\mathrm{CO}_{2}$ onto the hydrated formation of calcined oyster shell powders $\left[\mathrm{Ca}(\mathrm{OH})_{2}\right]$ as natural inorganic minerals through a carbonation process.

\section{Experimental Procedure}

Waste oyster shells have been collected from waterfronts of Namhae, and cleaned by alcohol and water to remove impurities attached onto the surfaces. Oyster shell powders dried in a drying oven were ground by a fine formation by using a comminution equipment, and were obtained to distributed size by sieving less than 100um for reproducible experiments. Waste oyster shell powder was calcined at ambient air condition inside an electric furnace under constant temperatures of $800^{\circ} \mathrm{C}$ and $1000^{\circ} \mathrm{C}$ for $1 \mathrm{~h}$ after arising as a temperature heating rate of $10^{\circ} \mathrm{C} / \mathrm{min}$. For surface analyses of waste oyster shell powders and the calcined powders, a scanning electron microscopy equipped with energy dispersive $\mathrm{x}$-ray spectroscopy (SEM-EDS) was employed and $10 \mathrm{~nm} \mathrm{Au}$ coating was conducted to provide surface conductivity on each powders. Through X-ray diffraction (XRD), crystallinities were measured for the calcined formation, the hydrated formation of calcined powders and the precipitated calcium carbonate formation of waste oyster shell powders, respectively. For thermal characteristics analysis, TG-DTA was conducted at ambient air condition at a temperature heating rate of $5^{\circ} \mathrm{C} / \mathrm{min}$ up to $1000^{\circ} \mathrm{C}$. The raw algal solution used in the present experiment was collected by direct pumping up from the place of sample collection for algal bloom study by K-Water at Daecheong Lake (Okcheon Chuso-ri, Busodamack) classified as a lake-type artificial reservoir in late October, 2015. Five test samples were prepared with 1 - $5 \mathrm{~g}$ of the waste oyster shell powders calcined at $1000^{\circ} \mathrm{C}$ and increased by the unit of $1 \mathrm{~g}$ in $200 \mathrm{~mL}$ algal bloom solution, respectively. For the prepared samples, visible changes in the water clarity and the light penetration were observed after undergoing the processes of coagulation ( 2 min agitation), precipitation ( $5 \mathrm{~min}), \mathrm{CO}_{2}$ flowing $(5 \mathrm{~min}$ ) at a gas flow rate of $0.5 \mathrm{~mL} / \mathrm{min}$, and re-precipitation $(5 \mathrm{~min}$ ). The measurement of $\mathrm{pH}$ alteration were measured in the step before $\mathrm{CO}_{2}$ flowing. The $\mathrm{CO}_{2}$ gas was injected for conversion to the precipitated calcium carbonate powders from hydrated formation of the calcined waste oyster shell powders. To measure the removal efficiencies of $\mathrm{PO}_{4}^{3-}$ by calcium, $\mathrm{Ca}\left(\mathrm{NO}_{3}\right)_{2}$ solution was prepared according to the concentration ratios of $\mathrm{Na}\left(\mathrm{PO}_{4}\right)_{3}$ at $\mathrm{pH} 12$. All water quality analyses were conducted by well-known conventional methods such as total nitrogen (chromotropic acid method, analyzed wavelength of $410 \mathrm{~nm}$, , analysis limit of $1.0 \sim 50 \mathrm{mg} / \mathrm{L}$ ), total phosphorous (ascorbic acid method, analyzed wavelength of $880 \mathrm{~nm}$, analysis limit of $0.01 \sim 3 \mathrm{mg} / \mathrm{L}$ ), and $\mathrm{COD}_{\mathrm{Mn}}$ (reactor digestion method, analyzed wavelength of $540 \mathrm{~nm}$, analysis limit of $0.6 \sim 20 \mathrm{mg} / \mathrm{L}$ ), measured by purchasing each test kit solutions with an UV-Visible Spectrophotometer (Humas. Co., LTD, HS-3300). In measuring the removal efficiencies for algal bloom, each solution was diluted by 5 times to avoid the effects of absorption wavelengths on green color of the raw algal solution. The results derived through total nitrogen(T-N), total phosphorus(T-P) and chemical oxygen demand $\left(\mathrm{COD}_{\mathrm{Mn}}\right)$ are plotted versus dispersed amount of calcined oyster shell powders into raw algae solution.

\section{Results and Discussion}

Detailed structures of an oyster shell were observed through SEM pictures on inner ( $1^{\text {st }}$ row, red dot), outer $\left(2^{\text {nd }}\right.$ row, yellow dot), cross-sectional ( $3^{\text {rd }}$ row, blue dot) surfaces of the waste oyster shells used in the present experiment (Fig. 1). Inner surface of the oyster shell consists of a visibly glossy plate structure, and the outer part consists of a dense structure of a shape connected to a larger round grain boundary than the inner part, while the cross-section consists of a layer by layered porous structure having a nanosize thickness. Fig. 2 shows the shape of comminuted powder of oyster shells before calcination (Fig. 2(a)), and after calcination at $800^{\circ} \mathrm{C}$ and $1000^{\circ} \mathrm{C}$ (Figs. 2(b) and 2(c)). Whereas a particle distribution of generally dense structure was observed before calcination, it was changed to a structure connected with peanut-shaped grains after undergoing the calcination process over $800^{\circ} \mathrm{C}$ in air. The two elements 

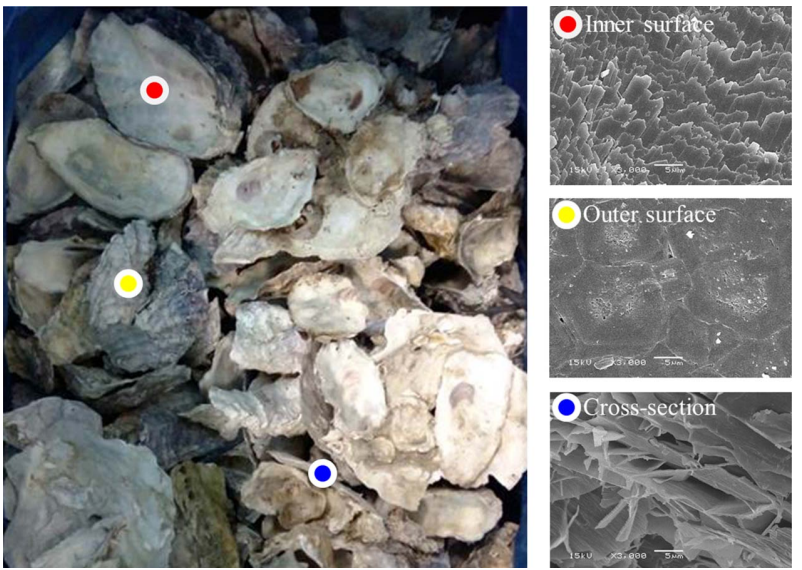

Fig. 1. SEM images on inner top view, outer top view and cross-sectional view of circular oyster shell surface.

showing the greatest change of EDS peak intensities in the conversion process from waste oyster shell powders to the calcined powders are carbon and oxygen. Based on the results of EDS peak intensities shown in Fig. 2(a) through Fig. 2(c), the ratios of $\mathrm{O} / \mathrm{Ca}$ and $\mathrm{C} / \mathrm{Ca}$ were calculated, respectively. The ratios of $\mathrm{O} / \mathrm{Ca}$ were gradually reduced through $0.39,0.14,0.13$, and the ratios of $\mathrm{C} / \mathrm{Ca}$ were also gradually lowered though $0.59,0.16,0.1$. From these observations, it could be considered that $\mathrm{Ca}$ atoms were exposed to most outer surfaces during continuous release of $\mathrm{CO}_{2}$ in the calcination process up to $1000^{\circ} \mathrm{C}$. Residual carbon peaks of the calcined waste oyster shell powders appeared at $1000^{\circ} \mathrm{C}$ are presumably attributable to scattering of the surrounding carbon tape, where it was actually prepared to completely pure $\mathrm{CaO}$ particle. This is substantiated by the clear XRD result for the calcined powders of waste oyster shells without any impurities shown in $1000^{\circ} \mathrm{C}$ of Fig. 3(a).

As shown in Fig. 3(a), the main chemical composition of waste oyster shell powders after comminution must be cal-
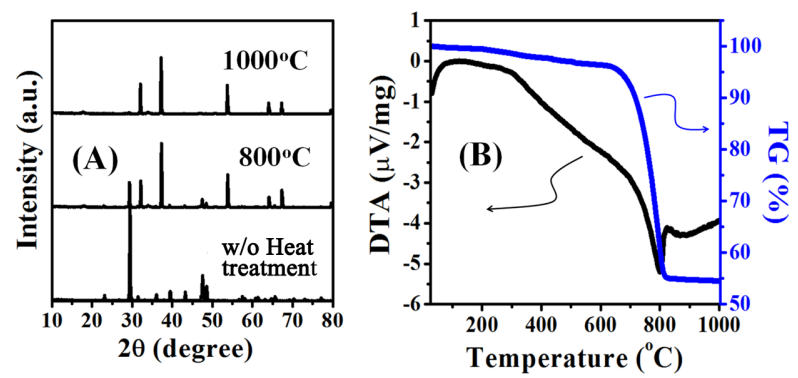

Fig. 3. XRD pattern and TG/DTA analysis of comminuted and calcined oyster shell powders.

cium carbonate $\left(\mathrm{CaCO}_{3}\right)$ with a hexagonal calcite crystal structure. After heat treatment at $800^{\circ} \mathrm{C}$, it is mixed calcium carbonate containing some of $\mathrm{CO}_{2}$ portion and most of crystalline $\mathrm{CaO}$ and has been changed to completely pure crystalline $\mathrm{CaO}$ at $1000^{\circ} \mathrm{C}$. In thermal decomposition behavior of the waste oyster shell powders (Fig. 3(b), calcination of the powders resulted in mass decrease of approx. $45 \%$ after undergoing continuous endothermic reaction between $300^{\circ} \mathrm{C}$ and $1000^{\circ} \mathrm{C}$ while a strongest endothermic peak was observed at about $800^{\circ} \mathrm{C}$. In view that the weight loss of powders began to be reduced at $650^{\circ} \mathrm{C}$, it is equivalent to a temperature where emission of $\mathrm{CO}_{2}$ began, and a quite small change of weight loss was observed after $850^{\circ} \mathrm{C}$ then the calcination to $\mathrm{CaO}$ was completed at $1000^{\circ} \mathrm{C}$.

Shown in Fig. 4 is the process where water clarity and light penetration were visibly changed through coagulation (with agitation), precipitation and carbonation reaction process. The $5 \mathrm{~g}$ addition of the calcined waste oyster shell powders was dispersed in the raw algal solution and was converted to the precipitated calcium carbonate powders after across above processes. Even though the coagulation and precipitation process of the waste shell powders, an rather improvement of water clarity was observed, a
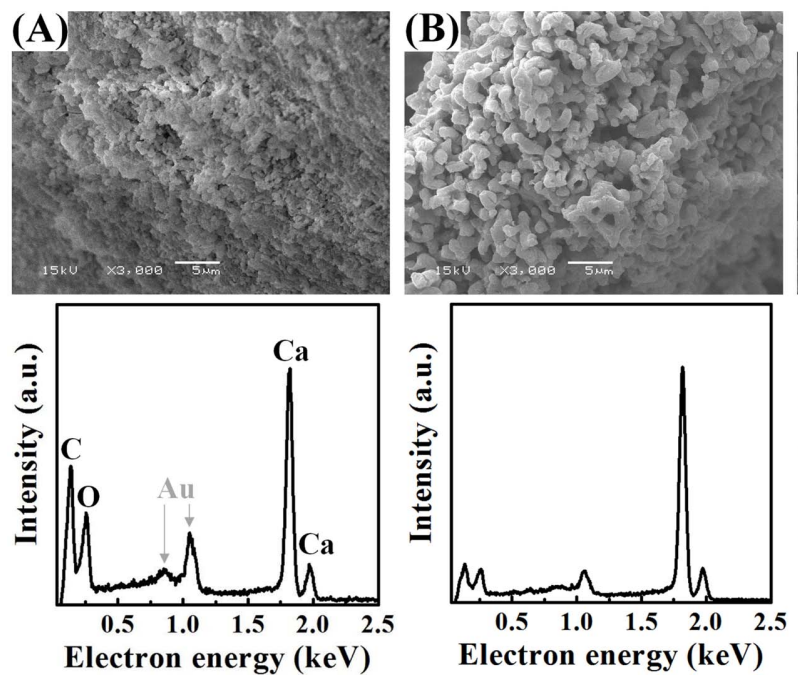
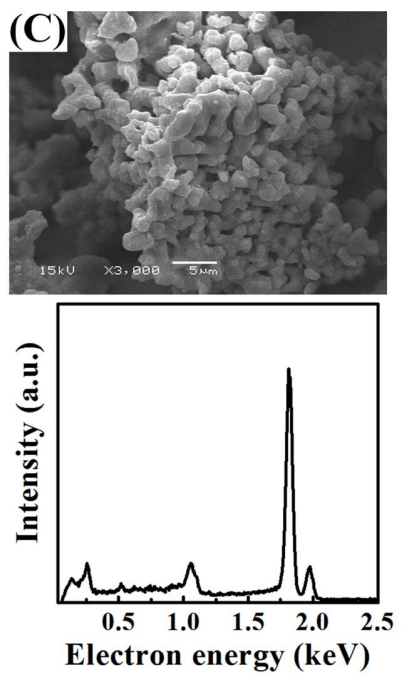

Fig. 2. SEM and EDS results of oyster shell powders without and with heat treatment: (a) comminuted powder, (b) $800^{\circ} \mathrm{C}$ and (c) $1000^{\circ} \mathrm{C}$. 

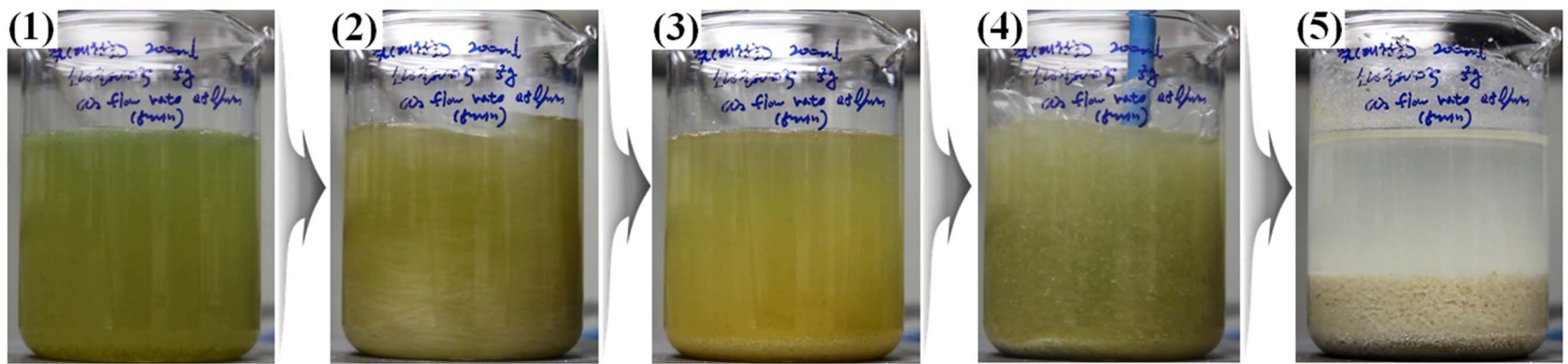

Fig. 4. Coagulation, precipitation and carbonation process of oyster shell powder for algae treatment acceleration: (1) $200 \mathrm{ml}$ amount of raw algal solution, (2) agitating of the calcined powder of 5 gram, (3) coagulation and precipitation process, (4) carbonation process by $\mathrm{CO}_{2}$ bubbling, and (5) water solution through accelerated algae treatment.
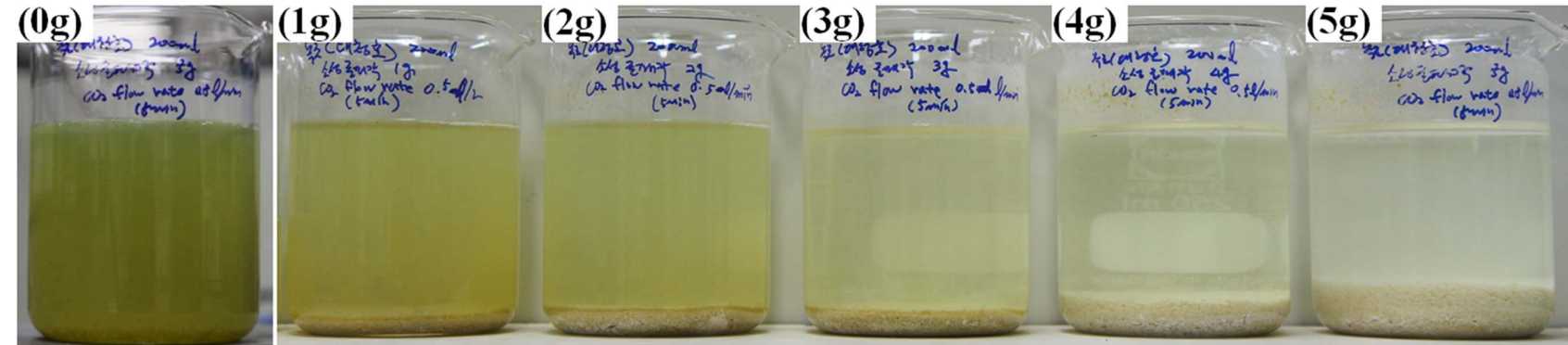

Fig. 5. Effects of amount on algae treatment performance of calcined oyster shell powders $(1-5 \mathrm{~g})$ through coagulation, precipitation and carbonation process.

remarkable transparency increase through water clarity and light penetration was accomplished with complete disappearance of green colored algal bloom, and occurred after undergoing carbonation reaction treatment to the precipitated calcium carbonate powders.

In Fig. 5, visible changes of raw algal solution in coagulation, precipitation and the carbonation reaction treatment are displayed as differences of dispersed amounts of the calcined waste oyster shell powders or of converted amounts to the precipitated calcium carbonate powders. When the fed powders amounts were given to be $1-5 \mathrm{~g}$ per $0.2 \mathrm{~L}$, it was changed from a green color of the raw algal solution to transparent colorlessness through a gradual improvement in water clarity and light penetration as the dispersed powder amounts were increased.

Figures 6 (a) and 6 (b) show a comparison of XRD patterns between before and after the carbonation reaction process converted to the precipitated calcium carbonate powders since coagulation, precipitation processes of the fed powders amounts are conducted to be $1-5 \mathrm{~g}$ per $0.2 \mathrm{~L}$. In Fig. 6(a), major peaks for waste oyster shell powders $\left(\mathrm{CaCO}_{3}\right)$, the calcined waste oyster shell powders $(\mathrm{CaO})$, and the hydrated formation $\left[\mathrm{Ca}(\mathrm{OH})_{2}\right]$ of calcined waste oyster shell powders are marked for an easy identification. In Fig. 6(b), all of precipitated powders are exhibited in a mixed form of the hydrated formation $\left[\mathrm{Ca}(\mathrm{OH})_{2}\right]$ of calcined waste oyster shell powders and the precipitated calcium carbonate powders $\left(\mathrm{CaCO}_{3}\right)$. Therefore, the hydrated formation $\left[\mathrm{Ca}(\mathrm{OH})_{2}\right]$ of calcined waste oyster shell powders and the precipitated
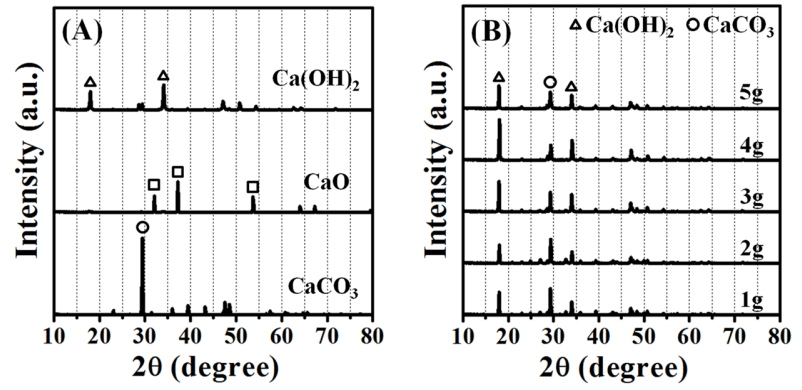

Fig. 6. XRD pattern of oyster shell powders before and after carbonation process: (a) carbonated, calcined and hydrated calcium mineral: $\mathrm{CaCO}_{3}, \mathrm{CaO}, \mathrm{Ca}(\mathrm{OH})_{2}$ and (b) precipitates with different weight $(1-5 \mathrm{~g})$.

calcium carbonate powders are considered to have competitively promoted algal bloom removal during coagulation, precipitation and carbonation process. For the reactant mass of $5 \mathrm{~g}$, a tendency where the increase of hydrated formation $\left[\mathrm{Ca}(\mathrm{OH})_{2}\right]$ of calcined waste oyster shell powders may be the reason that the powders are slowly settled down and some dispersed powders are uniformly floated as fine powders. Since the equivalent amounts of $\mathrm{CO}_{2}$ gas are injected, in order to perform accurate quantitative analysis between two powders, additional experiments are required to figure out the detail information for carbonation contents ratios reacted with between $\mathrm{CO}_{2}$ gas and hydrated formation. Continued additional experiments are also including concerning more precise water quality analyses with the 

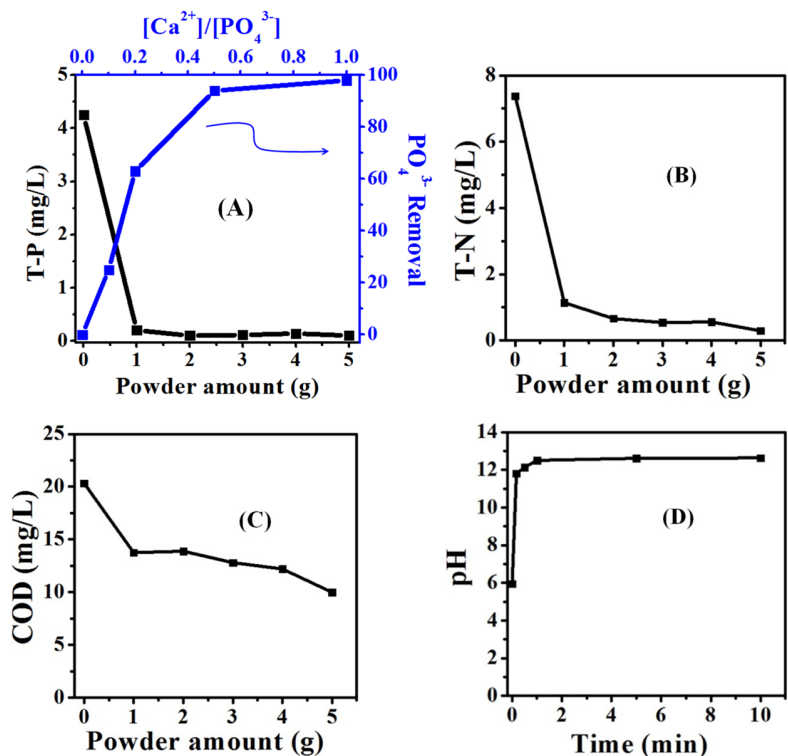

Fig. 7. Water treatment performance through accelerated carbonation process for organic algal and nutrient removal using calcined oyster shell powder: (a) T-P, (b) T-N, (c) COD, and (d) $\mathrm{pH}$ variation.

solutions before and after conduct carbonation process to the precipitated calcium carbonate powders for the raw algal solution.

The changes of T-P concentrations for all phosphorus-containing components as the dispersed amounts of calcined oyster shell powders were increased are shown in Fig. 7(a). For the total phosphorus load of raw algal solution $(0 \mathrm{~g} \rightarrow$ $\mathrm{T}-\mathrm{P}$ 4.25), T-P removal percentage was increased from $95 \%(1 \mathrm{~g} \rightarrow \mathrm{T}-\mathrm{P} 0.2)$ to $98 \%(5 \mathrm{~g} \rightarrow \mathrm{T}-\mathrm{P} 0.1)$ with the mean value of $97 \%$. In general, metal hydroxides are well known to be combined with $\mathrm{PO}_{4}^{3-}$ in the soil, which has been reported as being caused by electrostatic interactions and adsorption. ${ }^{20)}$ Considering the changes in the removal percentage of $\mathrm{PO}_{4}^{3-}$ anions with $\mathrm{Ca}^{2+}$ cations as a function of the concentration ratios of $\mathrm{PO}_{4}^{3-}$ anions $v s$. $\mathrm{Ca}^{2+}$ cations, the removal percentage of $\mathrm{PO}_{4}^{3-}$ anions was shown to be as high as 2-3 times at initially low $\mathrm{Ca}^{2+}$ cation concentrations, and then the absorbance tendency for $\mathrm{PO}_{4}^{3-}$ anions was approached to nearly $100 \%$ since the concentration of $\mathrm{Ca}^{2+}$ cations was exceeded a half of $\mathrm{PO}_{4}^{3-}$ anions.

For the concentrations of T-N in Fig. 7(b), T-N removal percentage was increased from $85 \%(1 \mathrm{~g} \rightarrow \mathrm{T}-\mathrm{N} 1.14)$ to $96 \%$ $(5 \mathrm{~g} \rightarrow \mathrm{T}-\mathrm{N} 0.29)$ with the mean value of $91 \%$ as the dispersed amounts of calcined oyster shell powders were increased when compared with T-N concentrations $(0 \mathrm{~g} \rightarrow \mathrm{T}-\mathrm{N}$ 7.38) in the raw algal solution. Basically, the COD value means the amount of oxygen dissolved in water through the organic algal bloom or the organic nutrients by photosynthesis and atmospheric replenishment. Therefore, a change of oxygen contents corresponds to amounts of precipitated organic nutrients or algal bloom. A COD reduction of about $51 \%$ was shown in Fig. 7(c), since the COD value of raw algal solution was changed to 20.33 to 9.00 as the dispersed powder amounts were $5 \mathrm{~g}$. The dispersed solution of calcined oyster shell powders was maintained a constant values of $\mathrm{pH}$ 12 - 13 after a rapid increase at initial reaction when the each powder was dispersed in the raw algal solution, as shown in Fig. 7(d). However, the higher $\mathrm{pH}$, unlike the algal bloom experiments on a laboratory level, is expected to be quickly neutralized in case of a wide water-flowing river after appearing a high performance with water quality improvement through algal bloom removal. T-N and T-P removal percentages (\%) together with $\mathrm{COD}$ reduction percentage (\%) for the waste oyster shell powders were obtained according to the following calculation equation;

$\mathrm{T}-\mathrm{N}, \mathrm{T}-\mathrm{P}$ removal percentage $(\%)=$

[Value applied to waste oyster shell / Raw algal solution] $\times 100$

COD reduction percentage $(\%)=$

[1 - (Value applied to waste oyster shell / Raw algal solution) $] \times 100$

In South Korea, the utilization scopes for practical uses based on COD, T-P, T-N, and so on are designated by the water quality environment standards for rivers and lakes revised by Ministry of Environment in $2006 .{ }^{21)}$ According to the results removing organic nutrients or organic algal bloom using the calcined waste oyster shell powders, the algal contaminated samples (collected from Daecheng Lake) was improved to the level of water quality allowing its use as industrial water with COD 10, T-P less than 0.15, and T$\mathrm{N}$ less than 1.5.

\section{Conclusions}

We demonstrated that the calcined waste oyster shell powders play a role of an excellent coagulant which could coagulate and precipitate the organic algal blooms or the organic nutrients such as phosphorous and nitrogen compounds causing eutrophication. Furthermore, it also utilize as a water-purifying substance which improved visible transparent with water clarity and light penetration. Through continuous carbonation reaction treatment, activation of coagulation and precipitation for removing organic algal blooms with organic nutrients were accelerated in the process where the hydrated formation calcined waste oyster shell powders was converted to the precipitated calcium carbonate powders. Finally, for the total pollutant load of raw algal solution, the mean T-P removal percentage was $97 \%$, the mean T-N removal percentage $91 \%$, and the maximum reduction of COD 51\%, respectively. Quick and effective technologies for removing severe algal bloom such as our trials are essential to sustainable utilization and development of water resources conforming to the regulations of Ministry of Environment. 


\section{Acknowledgements}

The authors are very grateful to the Korea Institute of Energy Technology Evaluation and Planning (KETEP) through the ETI program, Ministry of Trade, Industry and Energy (MOTIE, Project No. 2013T100100021) for financial support of this study.

\section{REFERENCES}

1. C. W. Lee, H. B. Kwon, H. P. Jeon, and B. Koopman, "A New Cycling Material for Removing Phosphorus from Water," J. Clean. Prod., 17 683-87 (2009).

2. H.-B. Kwon, C.-W. Lee, B.-S. Jun, J.-D. Yun, S.-Y. Weon, and B. Koopman, "Recycling Waste Oyster Shells for Eutrophication Control," Resour. Conserv. Recy., 41 75-82 (2004).

3. C.-W. Lee, H.-P. Jeon, and H.-B. Kwon, "Physical Properties of Pyrolized Oyster Shell Consisting of Porous $\mathrm{CaO} /$ $\mathrm{CaCO}_{3}$ and Phosphorus Removal Efficiency (in Korean)," J. Korean Ceram. Soc., 44 [6] 524-28 (2010).

4. S.-C. Lee, S.-G. Woo, Y.-D. An, H.-S. Jun, and H.-S. Koo, "An Experimental Study on the Structural Characteristics of Reinforced Concrete Beams Containing Oyster Shells (in Korean)," J. Korea Inst. Ecol. Archit. Environ., 7 [5] 135-42 (2007).

5. M.-J. Kim, X. Wang, J. J. Lee, S. H. Lee, S. B. Kim, and C.J. Kim, "Development of Flowable Backfill Material Using Waste Oyster Shell, Coal Ash, and Surplus Soil (in Korean)," Clean Technology, 19 [4] 423-29 (2013).

6. G. L. Yoon, K. S. Chae, and H. Yoo, "Experimental Investigation on Oyster Shell-Sand Mixtures (in Korean)," $J$. Korean Soc. Civ. Eng. C, 24 [5C] 283-88 (2004).

7. S.-H Lee, H.-J. Kim, Y.-C. Jung, and S.-K. Bae, "A Study on the Properties of Cement Mortar with Modified Oyster Shell Powder (in Korean)," J. Korean Ceram. Soc., 38 [3] 231-37 (2001).

8. S.-M. Cheon and T.-W. Song, "Study on Formation of Cement Clinker from the Mixture of Oyster Shell, Casting Dust and BOF Slag (in Korean)," J. Korean Ceram. Soc., 40 [12] 1235-40 (2003).

9. K.-H. Lee and T.-W. Song, "Study on the Synthesis of Tricalcium Aluminate Clinker from Waste Shell and Spent Oil-Refining Catalyst (in Korean)," J. Korean Ceram. Soc., 41 [12] 933-38 (2004).

10. H.-S. Lee, D. S. Woo, M.-S. Choi, D.-W. Park, J.-S. Yang and Y.S. Cho, "Research of Oyster Shell Recycled Coating Material and
Its Application to Filter Bed (in Korean)”, pp.1026-29 in $J$. Korea Acad. Industr. Coop. Soc., 2009.

11. M. H. Chong, B. C. Chun, Y.-C. Chung and B. G. Cho, "Fire-Retardant Plastic Material from Oyster-Shell Powder and Recycled Polyethylene," J. Appl. Polym. Sci., 99 158389 (2006).

12. H.-B. Kwon, C.-W. Lee, B.-S. Jun, J.D. Yun, S.-Y. Weon, and B. Koopman, "Recycling Waste Oyster Shells for Eutrophication Control," Resour. Conserv. Recy., 41 75-82 (2004).

13. H.-G. Choi, I.-H. Jeong, G.-R. Bae, J.-Y. Park, J.-J. Lee, Y.W. Kim, K.-S. jung, and S.-H. Kim, "A Proposition for the Removal of Algae and Phosphorus from River Water Using Multi-Purpose Filtration Pond (in Korean)," J. Kor. Soc. Environ. Eng., 35 [7] 525-31 (2013).

14. S. B. Seo, Y.-O. Kim, and C.-R. Kim, "A New Way for Incorporating GCM Information into Water Shortage Projections," Water, 7 2435-50 (2015).

15. J.-H. Huh, Y.-H. Choi, and J. W. Ahn, "Limestone Powders for Algae Treatment (in Korean)," Ceramist, 18 [3] 5-13 (2015).

16. S.-G. Kim, S.-K. Rhee, C.-Y. Ahn, S. R. Ko, G.-G. Choi, J.W. Bae, Y.-H. Park, and H.-M. Oh, "Determination of Cyanobacterial Diversity during Algal Blooms in Daechung Reservoir, Korea, on the Basis of $c p c B A$ Intergenic Spacer Region Analysis," Appl. Environ. Microb., 72 [5] 3252-58 (2006).

17. V. Smetacek and A. Zingone, "Green and Golden Seaweed Tides on the Rise," Nature, 504 84-8 (2013).

18. Y. K. Cha, S. S. Park, K. Kim, M. Byeon, C. A. Stow, "Probabilistic Prediction of Cyanobacteria Abundance in a Korean Reservoir Using a Bayesian Poisson Model," Water Resour. Res., 50 2518-32 (2014).

19. R. M. Kudela, E. Berdalet, S. Bernard, M. Burford, L. Fernand, S. Lu, S. Roy, P. Tester, G. Usup, R. Magnien, D. M. Anderson, A. Cembella, M. Chinain, G. Hallegraeff, B. Reguera, A. Zingone, H. Enevoldsen, and Ed Urban, "Harmful Algal Blooms," pp.1-19 in A Scientific Summary for Policy Makers, IOC/UNESCO, Paris (IOC/INF-1320) 2015.

20. R. P. J. J. Rietra, T. Hiemstra, and W.H.V. Riemsdijk, "Interaction between Calcium and Phosphate Adsorption on Goethite," Environ. Sci. Technol., 35 3369-74 (2001).

21. Water Environment Policy Bureau, "Amendment of Environmental Standard of Water Quality and Water Ecology. (in Korean)," pp. 19, Ministry of Government Legislation, Republic of Korea, 2006. 